\title{
Developing a Serious Game to Improve Reading Comprehension Skills in Third Graders
}

\author{
Laura S. Gaytán-Lugo ${ }^{1}$, Pedro C. Santana-Mancilla ${ }^{2}$, Alejandro Santarrosa- \\ García $^{2}$, Alex Medina-Anguiano ${ }^{2}$, Sara C. Hernández-Gallardo ${ }^{1}$ and \\ Miguel A. Garcia-Ruiz ${ }^{3}$ \\ ${ }^{1}$ Postgraduate and Research Dept., CUCEA, Universidad de Guadalajara, Mexico \\ ${ }^{2}$ School of Telematics, University of Colima, Mexico \\ ${ }^{3}$ Dept. of Computer Science and Mathematics, Algoma University, Canada \\ laura.gaytan@cucea.udg.mx,psantana@ucol.mx, asantarrosagarcia@gmail.com, \\ alkxnder@gmail.com, shernand@cencar.udg.mx,miguel.garcia@algomau.ca
}

\begin{abstract}
Results of different evaluations about reading comprehension in Mexico are not positive. Different methods and techniques have been implemented to counteract such numbers, and the support of serious games (video games that both entertain and educate) is one of them. Recently, video games demand has importantly increased in Mexico, which suggests that serious games can be successfully used by Mexican players. This paper presents the development and usability evaluation of a serious game intended to supporting and improving reading comprehension skills of third graders (ages 8-9 years old) from Mexico.
\end{abstract}

Keywords: Serious game, reading comprehension, third graders.

\section{Introduction}

Reading is a process that each person does by himself/herself and it allows to examine the content of what is being read, analyzing each part of the reading material, stressing the essential and comparing reader's already existing knowledge with the one that has been just acquired [1]. In essence, acquiring the ability to read and understand well is a basic requirement for the social and economic demands in today's society [2]. For [3], reading difficulties have important implications for the emotional development of children. Reading may represent a painful process that demands a great effort and is extremely frustrating for some children, which explains the development of a low motivation for academic achievement, low self-esteem and seriously compromises the prognosis of any therapeutic intervention.

\subsection{Reading Comprehension}

Reading comprehension is not just the mere decoding of meanings of a text, but the construction of meanings that result from the interaction of the reader with the text 
[4]. It is an act that takes time and effort to develop; it is impossible to demonstrate a lack of reading comprehension in children who have not yet learned to read with enough precision and fluency. Therefore, researches report that children at the age of 8 and older are the ones that start suffering the lack of such activity [5].

According to [6] readers acquire the meaning of a text by using skills and knowledge that involve different levels of complexity. This involves five processes: (1) global comprehension, where the reader considers the text as a whole and create a generally understand; (2) interpretation, where reader creates an idea based on the association of two or more parts of the text; (3) location or extraction of information, where the reader obtains specific data from the text through search, localization or selection of relevant information; (4) construction of the meaning of an expression. This happens when readers construct general or specific meaning that a term or expression acquired, and; (5) analysis of the content and structure, where the reader takes into account how the text is developed in order to reflect about its content, quantity and form.

\subsection{Serious Games}

One way of supporting the development of reading and to encouraging the reading in general is through playing video games. Some research studies show that video games encourage the acquisition of certain cognitive skills and improve student comprehension of learning materials presented through a video game [7].

Serious games are a genre of video games, and they are not used just for entertainment, but also for serious human spontaneous activities [8]. In addition, serious games use pedagogy to infuse instruction into the playing experience, and they are by nature suited to engage the learner and encourage active construction of meaning and development of skills.

Nowadays, serious games are receiving interest from researchers and industry because of the reasons explained above. In Mexico, on one hand, some scholars [910] have noticed this, and use serious games for different purposes. On the other hand, video games are already part of Mexico's daily use. In 2010, the video game Mexican market was worth $\$ 757$ million of U. S. Dollars, placing the country among the top 15 video game markets worldwide, being the first one from Latin America [11].

Taking into consideration all this lead us to think about the impact that video games can have in the field of reading comprehension, as proved by several studies on how they have been applied to education in different areas [12].

\section{Problem Statement}

Currently, there is a huge problem regarding reading comprehension in Mexico. According to a report written by [13], $41 \%$ of students do not reach basic skills level in reading comprehension. The Organization for Economic Co-operation and Development (OECD), which includes many highly-developed countries, estimates that Mexico would take 65 years to reach the current OECD's average in terms of 
reading comprehension. Regarding, reading comprehension and reflection on language in Spanish in Mexico at a national level, one in every four third graders is on the "Under basic" level, while $56 \%$ of them is on Basic level (Figure 1).

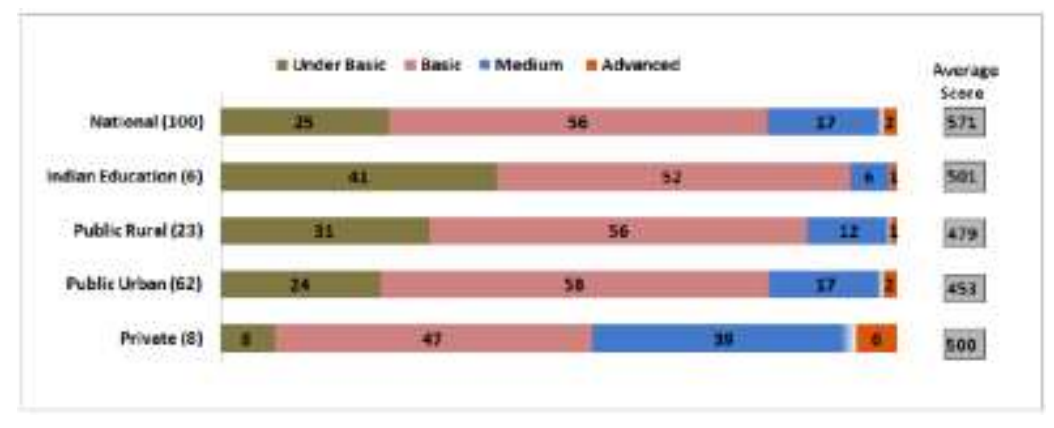

Fig. 1. Percentage of students by level of educational achievement and school stratum in Spanish.

\section{Method}

After making a systematic literature review, we chose to work with the User Centered Design (UCD), which is a design philosophy that involves a set of techniques that focus on knowing end user's needs, wants, limitations and context in each stage of the serious game design process and development life cycle [14].

Designing serious games for children brings with it different sets of demands and challenges, as children have different perceptions and make sense of the world around them differently from adults. Their ideas on motivating and fun aspects of technological systems may likely be different from what the adults can anticipate [15].

Our research project has the following steps:

1. Specifications of the context, where we identified the end users' main characteristics, in this case third graders; and under what conditions the project is going to operate.

2. Specifications of the user requirements, where we identify which skills the users need to improve [16], see Table 1.

3. Designing the solution, where it was were we held our greatest contribution, and that it is subdivided in the following stages: (a) video game design: in this phase we design menus, characters, scenarios, textures, scripts, among others; (b) development: we develop the actions and give functionality and interaction to the video game; (c) functionality test: in this step we make sure that there is no fatal or unexpected error when the end users are playing our serious game. 
Laura S. Gaytán-Lugo, Pedro C. Santana-Mancilla, Alejandro Santarrosa-García, et al.

4. Evaluation. We conducted a usability test to make sure problems are fixed and the serious game has a good functionality.

Table 1. Part of the obtained results on some of the problems that were part of the assessment instrument.

\begin{tabular}{|c|c|c|}
\hline Skill & Activity & $\overline{\bar{x}}$ \\
\hline $\begin{array}{l}\text { Global } \\
\text { comprehension }\end{array}$ & $\begin{array}{l}\text { Recognize the central message } \\
\text { of the text }\end{array}$ & 0.04 \\
\hline Interpretation & $\begin{array}{l}\text { Recognize, in an } \\
\text { advertisement, to whom the } \\
\text { message is directed to }\end{array}$ & 0.69 \\
\hline $\begin{array}{l}\text { Locate or extract } \\
\text { information }\end{array}$ & Locate specific information & 0.35 \\
\hline $\begin{array}{l}\text { Constructing the } \\
\text { meaning of an } \\
\text { expression }\end{array}$ & $\begin{array}{l}\text { Identify persuasive elements in } \\
\text { a commercial }\end{array}$ & 0.35 \\
\hline $\begin{array}{l}\text { Analyze the content } \\
\text { and structure }\end{array}$ & Identify a special condition & 0.21 \\
\hline
\end{tabular}

\section{Designing the Solution}

It is important to mention that the storyline, scripts, characters and scenarios were based on the needs of third graders [16].

\subsection{Designing Sprites}

We created sprites (two-dimensional images) that represented the following roles in our developed serious game: Main character, antagonist, secondary characters, scenarios, main elements, and menus.

In order to develop the scenarios, we took into account the plot and script of the game that was previously assigned to perform a design that was consistent with it. We also created graphical elements so the third graders could see, for example, how many coins the student has, health, time and score.

\subsection{User Interfaces and Menus}

User interfaces were previously prototyped with Balsamiq Mockups (www.balsamiq.com). 


\subsection{Development}

In this step of the project, we gave basic functions to the characters and scenarios of the game. For example motion has to be related with to the sprite that shows the character when it is moving, so it was necessary to create a script in Unity (http://unity3d.com) that should move the plane of the character through the plane of the scenario by using the keyboard arrows, and at the same time changing the orientation of the sprite coordinated with the plane motion as the plane of the character.

Once motion was provided to the character, it was necessary to establish limits within the scenario, so we implemented some features for 3D simulation games as the use of a physics engine

To set the necessary boundaries for delimiting the traffic area with objects of this type, we used walls with an attribute (rigidbody), so then, the character was unable to move through them and had no access to non-permitted areas of the game (see Figure 2).

In order to develop the scenarios, we took into account the plot and script of the game that was previously assigned to perform a design that was consistent with it. We also created graphical elements so the kids could check, for example, how many coins the student has, health, time and score.

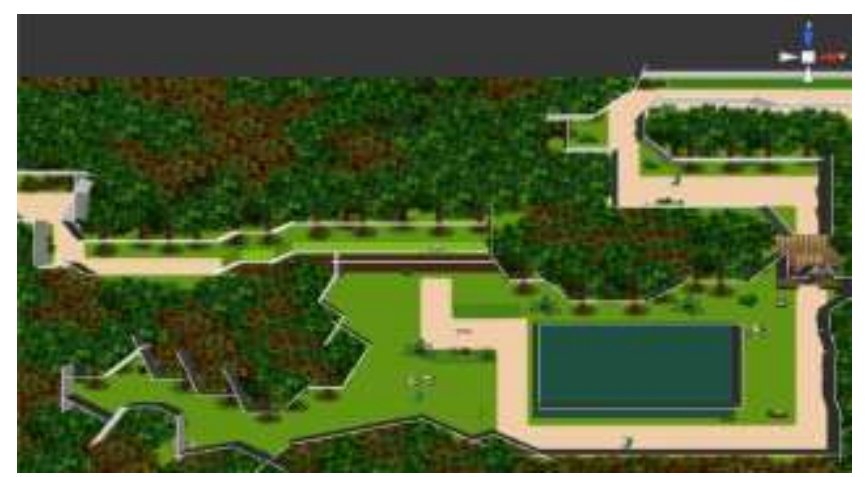

Fig. 2. Scenario with barriers and traffic areas.

\subsection{Evaluation}

A study was conducted by third graders to measure the usability and acceptance of our serious game.

\section{Procedure}

Phase 1: Students were given a 10 minute introduction to study the serious game. 
Laura S. Gaytán-Lugo, Pedro C. Santana-Mancilla, Alejandro Santarrosa-García, et al.

Phase 2: We performed a live demo showing the students the game features. The aim of this was to put in context the use of the controls to the participants.

Phase 3: The participants were given a task list to complete on the game.

Phase 4: Participants were asked to complete a game heuristics questionnaire and a game experience questionnaire (GEQ) with two dimensions.

\section{Results and Discussion}

\section{Game Heuristic Questionnaire}

We applied the game heuristics questionnaire to the participants with the following items:

H1: Does the game reacts in a consistent way to the player's actions?

H2: Could you customize the profile, music, video, and the game difficulty and speed?

H3: Could you find a predictable and reasonable behavior of the controls?

H4: Does the game provide information about an action to take?

H5: Can the player can skip not-playable content (i.e. videos or texts) to return to the game?

H6: Are the controls intuitive and customizables?

H7: Are the game controls consistent within the game?

H8: Does the game present information about the game status?

H9: Does the game provide instructions, help and training?

H10: Are the status score indicators seamless, obvious, available and do not interfere with game play

Participants found that the game controls were consistent, predictable, intuitive with reasonable behavior and customizable (see Figure 3). Also, they believed that the game presented quality and usable information about its status, actions to take and provided useful instructions, help and training. 


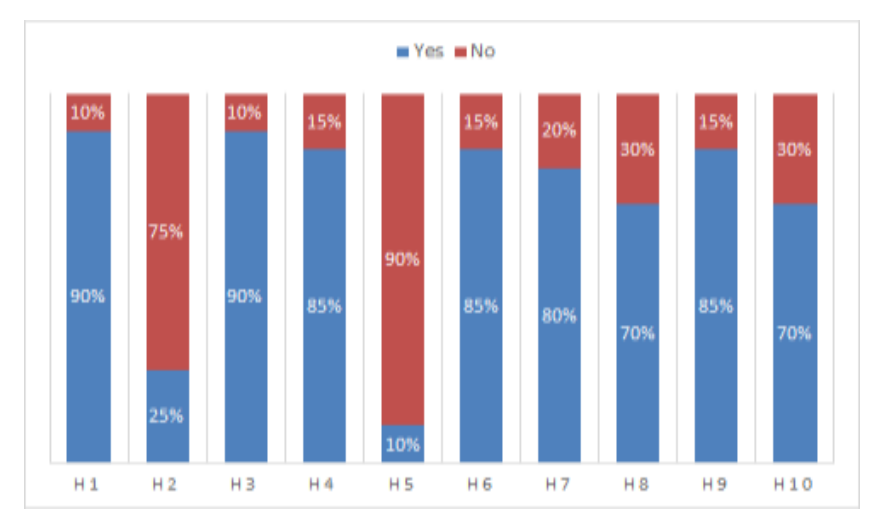

Fig. 3. Game heuristics questionnaire.

Two heuristics got bad results: $\mathrm{H} 2$ and $\mathrm{H} 5$. $\mathrm{H} 2$ is related to game customization; the participants found few options to customize the game. It is a good area of opportunity for improving the game usability. H5 is about skipping the not-playable content. This game was developed to improve the child reading comprehension and on a big part of the gameplay the user had to read several paragraphs; in order to achieve this goal it was important not to skip these paragraphs.

\section{Game Experience Questionnaire}

The GEQ is divided into two parts: (1) four questions, where the participants had to give a grade from 1 to 10 , where 10 is the most significant, and (2) seven questions that measured efficiency, effectiveness, immersion, motivation, emotion, fluency. It had a 5 item Likert scale.

The first part of the GEQ included the following questions:

Q1: Did you find the game fun?

Q2: Was it difficult to adapt to the game control?

Q3: Did you find the game exciting?

Q4: How easy it was to fulfill the objective of the game?

Figure 4 shows the ratings obtained on this section of the evaluation.

In this part of the GEQ, participants found the game fun and exciting, with a low difficult to adapt with the control; but they believed that the game was slightly difficult to fulfill its objective. The four questions got an average grade of above 9 . 


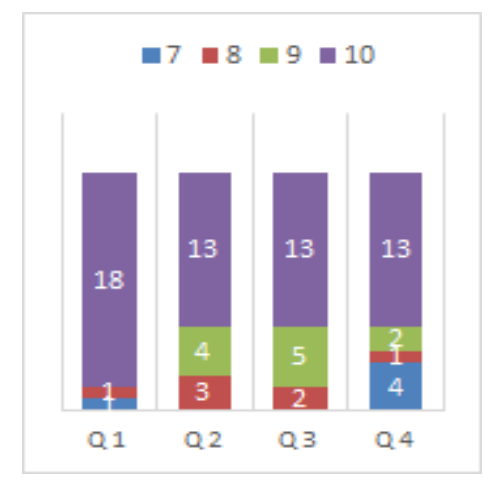

Fig. 4. GEQ first dimension.

As mentioned, the second part measured seven indicators. Figure 5 shows the results of this part. $90 \%$ of participants perceived the game as efficient, immersive and fluent; $85 \%$ thought it was effective; the game provided motivation and emotion to $80 \%$ of the users; and finally we found the weakness on the learning curve with a $75 \%$, but it is still an acceptable percentage.

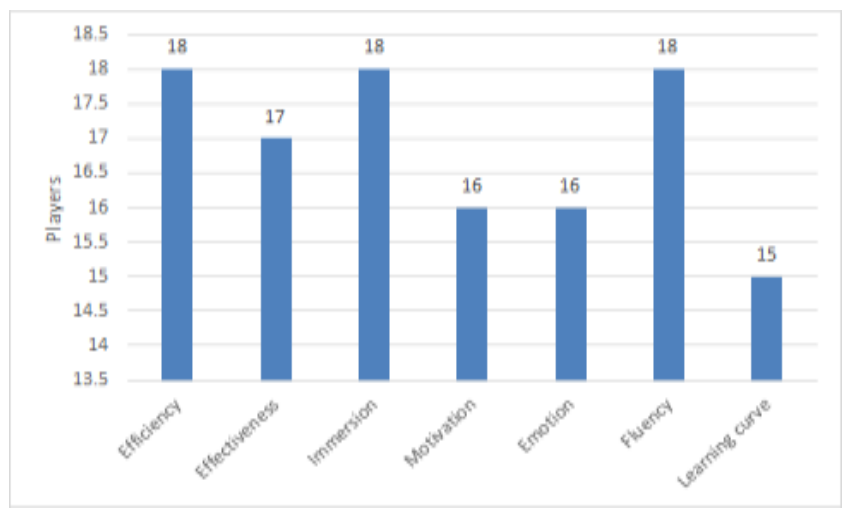

Fig. 5. GEQ second part.

\section{Conclusions}

Taking into account the participants' desire was always a good idea as our usability evaluation showed good intentions of using the game for educational purposes and thus we obtained good results on its usability. In addition, we spent great time working with children. We even learned from them aspects about usabitily that we have not had in mind first. 


\section{Future Work}

We are going to improve the serious game thanks to the participants' feedback. After that, we are going to evaluate the educational part of the game, which means that we have to make sure that the game will effectively improve the reading comprehenion skills that we mentioned before.

\section{References}

1. Perrusquia, E., Carranza, L., Vázquez, T., García, M., Meza, F.: Curso básico de formación continua para maestros en servicio, planeación didáctica para el desarrollo de competencias en el aula 2010. Subsecretaria de Educación Básica, SEP (2010)

2. De Coster, I., Motiejunaite, A., Noora, S. Teaching readin Europe; Context, Policies and Practices, http://eacea.ec.europa.eu/education/eurydice

3. Gómez-Velázquez, F., González-Garrido, A., Zarabozo, D., Amano M.: La velocidad de denominación de letras. El mejor predictor temprano del desarrollo lector en español. Revista Mexicana de Investigación (2010)

4. Graffigna, M. Luna, A., Ortiz, A., Pelayes, A., Rodríguez-Manzanares, M., Valera, C.: Lectura y comprensión de textos en el nivel superior: un desafío compartido entre alumnos y docentes. Revista Iberoamericana de Educación (2008)

5. Nation, K., Cocksey, J., Taylor, J., Bishop, D.: A longitudinal investigation of early reading and language skills in children with poor reading comprehension. Journal of child psychology and psychiatry, and allied disciplines, (2010)

6. INEE, http://www.sep.gob.mx

7. Conolly, T., Stansfield, M., Boyle, L..: Games-Based Learning Advancements for MultySensory Human Computer Interfaces: Techniques and Effective Practices. IGI Global Publishing.

8. He, L., Hu, X., Wei, D.: The case analysis of Serious Game in community vocational education. In: Proceedings of 2011 International Conference on Computer Science and Network Technology (2011).

9. Gaytán-Lugo, L., Hernández-Gallardo, S.: Towards Improving Reading Comprehension Skills in Third Graders with a Serious Game. In: Proceedings of the $20^{\text {th }}$ International Conferences of Computers in Education, Singapore (2012)

10. L. A. Zavala, S. C. H. Gallardo, M. Á. García-Ruíz: Designing Interactive Activities within Scratch 2.0 for Improving Abilities to Identify Numerical Sequences. In: Interaction Design Children, pp. 423--426 (2012)

11. PROMEXICO, http://mim.promexico.dob.mx

12. Squire, K., http://website.education.wisc.edu/kdsquire/dissertation.html

13. OECD.: PISA 2012 Result in focus. What 15 years old know and what they can do with what they know. Technical report (2013)

14. Moreno-Rocha, M., Martínez-Sandoval, C.: Desarrollo del Proyecto de Red Contextual. In: Congreso Internacional de Tecnologías de Información 2012, Colima (2012)

15. Tan, J., Goh, D., Ang, R., Huan, V.: Child-centered interaction in the design of a game for social skills intervention. ACM Computers in Entertaiment (2011)

16. Gaytán-Lugo, L.: Valoración de las habilidades de comprensión lectora en estudiantes de tercer grado de primaria: rumbo al diseño de un juego serio. In press. 